\title{
A novidade que empolga - O PCB e a Frente Popular Alagoana de 1986
}

\author{
The novelty that excites - The Brazilian Communist Party and the 1986's Alagoas \\ Popular Front
}

Rodrigo José da Costa*

\begin{abstract}
Resumo
O objetivo deste artigo é analisar a participação da Seção Alagoana do Partido Comunista Brasileiro (PCB-AL) na Frente Popular Alagoana, uma coligação de partidos políticos de esquerda cuja arregimentação visava a disputa das eleições de 15 de novembro de 1986. Composta pelo Partido Socialista Brasileiro (PSB), Partido dos Trabalhadores (PT) e Partido Democrático Trabalhista (PDT), a "Frente" procurou se constituir como uma alternativa diante dos dois grandes blocos políticos existentes, capitaneados pelo PMDB e pelo PFL. Procuro abordar os debates e os impasses surgidos na organização da Frente, o posicionamento de seus atores políticos e os desafios enfrentados, principalmente pelo PCB, no cenário político recém-inaugurado da Nova República. Inserido num esforço de pesquisa mais amplo, este trabalho visa contribuir com um período ainda pouco estudado da trajetória pecebista, o período compreendido entre a reorganização do partido no fim da década de 1970 e início da seguinte, um interregno de tempo no qual a agremiação se reestruturou, obteve a legalidade e, por fim, a extinção diante da crise resultante das transformações, tanto internas quanto externas, pelas quais passava o mundo comunista no período em que a Guerra Fria caminhava para o seu fim. Da mesma maneira, procuro adentrar numa temporalidade ainda pouco abordada pelos historiadores, que só recentemente tem dado atenção ao processo de transição o qual restabeleceu o regime liberal democrático no país.
\end{abstract}

Palavras-chave: Partido Comunista Brasileiro. Nova República. Eleições de 1986. Partidos políticos.

\begin{abstract}
The aim of this paper is to analyze the participation of Alagoas Section of the Brazilian Communist Party (PCB-AL) in Alagoas Popular Front, a coalition of leftist political parties whose regimentation aimed to contest the elections of November, 15th 1986. Composed by Brazilian Socialist Party (PSB), the Workers Party (PT) and Democratic Labour Party (PDT), the "Front" tried to be as an alternative before the two major existing political blocs, led by the PMDB and the PFL. I try to approach the debates and dilemmas arising in the organization of the Front, the positioning of its political actors and the challenges faced, especially by the PCB, the newly opened political landscape of the New Republic. Inserted in a broader research effort, this work aims to contribute to a period still understudied of the communist trajectory: the period from the reorganization of the party in the late 1970s and early next; a gap of time the college was restructured, obtained the legality and finally extinction before the crisis arising from the transformations, both internal and external, he passed the communist world in the period when the Cold War walked to its end. Likewise, I try to enter a temporality still poorly addressed by historians, who only recently has paid attention to the transition process that restored the liberal democratic regime in Brazil.
\end{abstract}

Keywords: Brazilian Communist Party; New Republic; 1986 elections; Political parties.

\footnotetext{
* Doutorando em História pela Universidade Federal de Pernambuco (UFPE). Professor da Universidade Federal de Alagoas (UFAL). Bolsista do Conselho Nacional de Desenvolvimento Científico e Tecnológico $(\mathrm{CNPq})$.
} 
As eleições estaduais de 1986 foram um marco no restabelecimento do regime liberal-democrático no Brasil. Recém-saído de uma ditadura que durara mais de duas décadas, o país foi às urnas em 15 de novembro para a escolha de governadores - cuja eleição direta havia sido suspensa ainda na década de 1960 e somente foi permitida nas eleições anteriores, em 1982. No período anterior, a escolha do executivo estadual foi feita de forma indireta pelos governos militares. O presente pleito, que também visou à composição das Assembleias e Câmara Legislativas, carregava um significado mais importante: a eleição da bancada federal responsável pela elaboração da nova carta constitucional, instrumento, sobretudo simbólico, que selaria de vez o rompimento com a legislação autoritária herdada da ditadura.

Para o Partido Comunista Brasileiro (PCB) essas eleições também marcaram um momento especial. Com pouco mais de um ano de vida legal e, já àquela altura, o mais longevo partido do cenário político nacional, o PCB, que durante grande parte de sua existência havia sido compelido à clandestinidade, concorreu às eleições com candidatura própria, sem precisar que seus militantes recorressem a outras legendas para disputarem o pleito.

Apesar de a decretação da anistia e a consequente volta de muitos dos membros do Comitê Central exilados possibilitarem um reagrupamento dos comunistas do PCB em território nacional, o partido vivia um momento delicado. Se, em tese, sua política de superação do regime militar a partir da formação de uma ampla frente democrática seria cada vez mais coroada de êxito, os desdobramentos do processo de abertura iniciado na segunda metade da década de 1970, a emergência do Novo Sindicalismo e o surgimento de outros partidos políticos - que ao reivindicar a representação dos trabalhadores, se tornavam concorrentes do PCB, como o Partido dos Trabalhadores (PT) -, além das baixas que o partido sofrera durante a ditadura, impuseram uma série de obstáculos cuja resposta deveria ser imediata.

As forças políticas e sociais vinculadas ao movimento operário e popular derrotadas em 1964, mesmo atordoadas, passaram a refletir sobre os motivos da derrota e sobre o que fazer para organizar e travar a luta de resistência. Para os agrupamentos que se encontravam à esquerda do PCB - como o PCdoB, a AP e a Polop - o problema estava no fato de se depositar confiança demasiada no governo nacional burguês e de as massas não terem sido preparadas para resistir ao golpe de maneira organizada e armada (REIS FILHO, 1990). Daí a convicção de que a resistência a e a derrocada da ditadura teriam de ser pela via das armas e com respaldo popular amplo. Uma parte muito 
significativa do PCB também tendeu a seguir essa avaliação, o que se explicitou nos encontros preparatórios do VI Congresso, realizado em 1967, ao ponto de se gerar diversas cisões (REIS FILHO, 1990, p. 47) ${ }^{1}$.

No entanto, para a militância que seguiu essa orientação, o drama iniciado em 1964 se transformou em tragédia, com a luta desigual travada contra o Estado entre 1969 e 1973. Na visão de Marcos Del Roio,

[...] a exacerbação da violência estatal e paramilitar, o reforço do corporativismo, o discurso ideológico pseudonacionalista e principalmente o predomínio do capital bancário/financeiro eram indícios de um processo de fascistização, que foi barrado pela oposição liberal burguesa e pela oposição popular (indiretamente auxiliadas pela crise energética mundial). (DEL ROIO, 2014, p. 8-9).

Desde o início do período, a maioria do PCB defendia a unidade entre as forças populares e a oposição liberal para derrotar a ditadura e instaurar uma nova democracia a partir de uma assembleia constituinte. Ainda de acordo com o autor, essa posição ganhou força depois de 1974, "perante divisões no Estado e na burguesia diante da fascistização e o crescente descontentamento popular de tamanha exploração do trabalho e violência estatal".

No Estado, em particular nas Forças Armadas, havia uma posição favorável à permanência da situação de excepcionalidade e exacerbação do corporativismo - que ocupou o governo com o general Geisel - e outra que se empenhava em garantir instituições estáveis, o que exigiria a cessação da perseguição política e cultural sistemática e a concessão de espaços efetivos para a oposição liberal e para a Igreja Católica. A oposição popular de esquerda marxista estava terrivelmente fragilizada por conta da repressão, a qual continuou atuando com denodo contra os comunistas até 1976, cujos efeitos foram devastadores. Com isso, a esquerda católica pode ocupar espaços maiores em se considerando ter melhores condições de defesa contando com o respaldo institucional da Igreja. Mesmo assim, a política de frente dos comunistas angariou frutos, e a pressão popular difusa deslocou uma área liberal para o campo da

\footnotetext{
${ }^{1}$ O lapso temporal transcorrido entre o golpe e o VI Congresso, realizado em 1967, marcou o período de fragmentação do PCB em uma série de miniorganizações que se multiplicaram pelos anos seguintes. Se, por um lado, o PCB atribuía ao "esquerdismo" a responsabilidade pelo golpe, para as correntes internas, as quais começavam a discordar da linha geral do Partido, pelo contrário, adviria do "direitismo" as causas da derrota. Para os primeiros, tratava-se de esconjurar os líderes nacionalistas e comunistas que quiseram ir longe demais. Para os segundos, era necessário fazer rolar as cabeças dos dirigentes do PCB, a de Prestes em particular. Sobre os acontecimentos decorrentes da fragmentação do PCB ver GORENDER, Jacob. Combate nas trevas. A esquerda brasileira: das ilusões perdidas à luta armada. $4^{\mathrm{a}}$ ed. São Paulo: Ática, 1990.
} 
democracia, incluindo algumas lideranças intelectuais em particular (DEL ROIO, 2014, p. 8-9).

No começo da década de 1980, o debate em torno da questão democrática ressoou forte no interior do PCB. Muitos dos que defenderam a manutenção da proposta de frente ampla contra a ditadura e combateram a concepção instrumental da democracia adotada no passado se encontravam agora em uma encruzilhada. Para alguns de seus militantes, a organização havia se distanciado dos princípios revolucionários e perdido sua identidade de classe. Em vez de assumir o papel de vanguarda do proletariado, o PCB estava se transformando num partido reformista, próximo da social democracia (PANDOLFI, 2007, p. 226).

Maria Alice Carvalho (2007) aponta que, quando o PCB aprofunda sua orientação democrática em meio a um intenso movimento de massas contra o regime militar, era razoável supor que o acerto de sua política favorecesse a elaboração de uma práxis coerente com ela. Mas, na visão da autora, "o PCB não soube ganhar" (CARVALHO, 2007, p. 264). E a experiência acumulada na luta por uma sociedade progressivamente mais justa e democrática, se não se perdeu de todo - pois acabou incorporada como ponto de passagem obrigatório à reflexão de esquerda no Brasil -, não lhe serviu como plataforma para sua própria refundação.

É assim que, em fins da década de 1970, o argumento democrático se desvencilhou da sua subordinação à questão nacional, estabelecendo-se a conquista das liberdades democráticas como foco central da luta comunista. Em maio de 1978, se consagrou a via eleitoral como "forma superior de luta" e, em novembro daquele mesmo ano, uma nova resolução política do Comitê Central sustentou que, para os comunistas, "luta pela democracia é parte integrante da luta pelo socialismo", sendo a frente antifascista indiferente aos interesses econômicos das forças que a compunham.

Muitos fatores colaboraram para a vitória, naquele momento, da concepção de democracia progressiva, considerando-se que tal concepção não era inteiramente estranha à Declaração de Março de 1958 e ao VI Congresso, em 1967. Mas, em ambos, persistiu um viés terceiro-mundista, o que conferiu limites severos à nova identidade que a questão democrática fomentava entre a militância comunista.

Não obstante a esses impasses, em 1980, houve o rompimento do secretário geral do PCB, Luís Carlos Prestes, o qual ocupara o cargo desde a década de 1940. Discordando da linha assumida pelo partido, Prestes, que se encontrava exilado em Moscou desde 1971, viu fortalecer-se a corrente antiprestista no interior da agremiação. 
O "Cavaleiro da Esperança" foi acusado por seus companheiros de ser "personalista, caudilho, autoritário e esquerdista." (PANDOLFI, 2007, p. 237).

Em março de 1980, Prestes, que havia retornado ao Brasil em outubro de 1979 após oito anos de exílio forçado, beneficiado com a decretação da anistia, elaborou uma "Carta aos Comunistas", criticando as posições "reformistas" assumidas pelo partido. Denunciava a falência da direção, responsabilizando-a pela prisão e morte dos dez membros do Comitê Central assassinados pelos órgãos policiais em 1974. Destituído do cargo de secretário-geral, que passou a ser ocupado por Giocondo Dias, Prestes, procurou, sem sucesso, o apoio da União Soviética. Em junho de 1980, juntamente com sua mulher, viajou a Moscou para apresentar suas divergências com os comunistas brasileiros. Em vão. O interlocutor privilegiado dos soviéticos era o PCB, não mais Prestes.

De acordo com Anita Leocádia Prestes, convencido do abandono por parte da direção do PCB de seus objetivos revolucionários consagrados nos documentos partidários, Prestes, tendo compreendido que não havia condições para organizar de imediato um partido revolucionário no Brasil, iria dedicar os últimos dez anos de sua vida a difundir suas ideias, principalmente junto aos trabalhadores e aos jovens (PRESTES, 2014, p. 119-120) $)^{2}$. Ao mesmo tempo, procuraria participar, ao lado de seus apoiadores, da vida política nacional, com o objetivo de acumular forças e contribuir para a criação das condições propícias ao surgimento de organizações efetivamente revolucionárias, habilitadas a conduzir a realização das transformações necessárias ao advento do socialismo no país.

Prestes percorreu todo o Brasil a convite das mais diversas entidades sociais, de trabalhadores, de estudantes, de intelectuais, de políticos e de numerosos admiradores. Participou das principais campanhas eleitorais, procurando sempre dar apoio aos candidatos comprometidos com as causas populares e dispostos a contribuir para o avanço real da democratização do país.

Dito isso, meu objetivo neste artigo é analisar a participação da seção estadual do PCB na Frente Popular alagoana, composta por outros partidos de esquerda, tais como o Partido Socialista Brasileiro (PSB), o Partido dos Trabalhadores (PT) e o Partido Democrático Trabalhista (PDT), que se arregimentou com o objetivo de

\footnotetext{
${ }^{2}$ Também em 2014, o historiador Daniel Aarão Reis publicou a biografia do líder comunista, abarcando toda a sua trajetória política e pessoal ao longo de praticamente todo o século XX. Ver: Daniel Aarão Reis (2014a), Luís Carlos Prestes.
} 
participar das eleições estaduais em 1986. Nas linhas que seguem, procurarei abordar os debates e os impasses surgidos na organização da Frente, o posicionamento de seus atores políticos e os desafios enfrentados, principalmente pelo $\mathrm{PCB}$, no cenário político recém-inaugurado da Nova República.

Inserido num esforço de pesquisa mais amplo $^{3}$, este artigo visa discutir resultados preliminares sobre um período ainda pouco estudado da trajetória pecebista, tomando como marcos a reorganização do partido no fim da década de 1970 até os momentos iniciais da Nova República, quando a agremiação se reestruturou e obteve a legalidade para, em seguida, diante da crise resultante das transformações, tanto internas quanto externas, pelas quais passava o mundo comunista no período em que a Guerra Fria caminhava para se extinguir. Da mesma maneira, procuro adentrar numa temporalidade ainda pouco abordada pelos historiadores, que só recentemente tem dado atenção ao processo de transição, o qual restabeleceu o regime liberal democrático no país. ${ }^{4}$

As fontes utilizadas neste trabalho tiveram o seu sustentáculo em dois acervos distintos, contudo, complementares. O primeiro compreende os documentos dos planos de organização e de campanha nos processos eleitorais do PCB alagoano, organizados e publicados por Geraldo Majella no livro O PCB em Alagoas: documentos (19821990). O segundo grupo foi originário do Fundo Geraldo Majella, disponível no portal Memórias Reveladas (www.an.gov.br/mr). Assim como os documentos que foram compilados no livro, as fontes disponíveis nesse fundo pertenceram, durante muito tempo, ao arquivo privado de Geraldo Majella, historiador alagoano e ex-militante comunista na década de 1980, os quais na vigência do Projeto Memórias Reveladas ${ }^{5}$ em 2010, foram doados ao Arquivo Público de Alagoas.

\footnotetext{
${ }^{3}$ Os resultados apresentados neste texto dizem respeito a uma parte da pesquisa de doutoramento que venho realizando junto ao Programa de Pós-Graduação em História da Universidade Federal de Pernambuco.

${ }^{4}$ Apesar do aumento exponencial em relação ao número de pesquisas e de trabalhos publicados sobre o Golpe Civil e Militar bem como relativos à Ditadura que o sucedeu, ainda são relativamente poucos os trabalhos que tratam do período final do Regime Militar, algo idêntico ao período de transição para a Nova República. Cito dois exemplos que desafiam essa lacuna, os trabalhos de Daniel Aarão Reis (2014b) e Francisco Carlos Teixeira (2010).

5 O Centro de Referência das Lutas Políticas no Brasil, denominado "Memórias Reveladas", foi institucionalizado pela Casa Civil da Presidência da República e implantado no Arquivo Nacional com a finalidade de reunir informações sobre os fatos da história política recente do País. Em novembro de 2005, foi assinado o decreto regulamentando a transferência para o Arquivo Nacional dos acervos dos extintos Conselho de Segurança Nacional, Comissão Geral de Investigações e Serviço Nacional de Informações, até então sob custódia da Agência Brasileira de Inteligência (Abin). O Centro constitui um marco na democratização do acesso à informação.
} 


\section{A formação da Frente: debates e impasses}

As articulações para a criação da Frente Popular alagoana, que disputou as eleições de 15 de novembro de 1986, começaram a ser tecidas já no início daquele ano. O programa da Frente começou a ser discutido concretamente já na primeira semana de fevereiro. Em princípio, seria formado um colegiado com dois representantes de cada um dos quatro partidos e cada um apresentaria um esboço dos principais interesses políticos de cada legenda (COLEGIADO..., 1986) ${ }^{6}$. Em uma entrevista a um programa de rádio de Maceió, o jornalista Anivaldo de Miranda, explicou que:

Esta Frente Popular não é de esquerda, não é socialista, não é comunista. É
como o próprio nome diz, uma alternativa concreta em busca de verdadeiras
mudanças. Por isso mesmo vamos tentar elaborar um programa de trabalho
único, onde estejam todas as principais reivindicações da população e que são
igualmente destes partidos que a compõem. (COLEGIADO..., 1986, p. A-3). ${ }^{7}$

Ainda de acordo com o entrevistado, a Frente Popular vinha sendo reforçada a cada dia, fator que havia suscitado interesse de alguns "grupos progressistas" - assim nomeados por Miranda - do Partido do Movimento Democrático Brasileiro (PMDB), depois que alguns membros participaram da reunião da Frente na semana anterior. Dessa reunião participaram representantes de todos os partidos que compunham a Frente Popular, além da deputada Selma Bandeira e dos vereadores Freitas Neto, Guilherme Falcão, Fernando Costa e Kátia Born.

Uma vez elaborado o programa, o passo seguinte seria o lançamento oficial em praça pública da Frente Popular, além do lançamento de um jornal que traduzisse exatamente os princípios defendidos por ela. Segundo Miranda,

Vamos partir para discutir coisas concretas verdadeiramente. Porque até agora falou-se em mudanças, mas nada mudou neste Estado. É isso que a Frente Popular se predispõe. Concretizar as aspirações mais urgentes da classe trabalhadora, do homem do campo, do morador da periferia etc. (COLEGIADO..., 1986) ${ }^{8}$.

Aspecto importante a ser observado na declaração de Miranda é a sua preocupação em afirmar que a "Frente Popular não é de esquerda, não é socialista, não é

\footnotetext{
${ }^{6}$ COLEGIADO irá elaborar agora o programa da Frente Popular. Jornal de Alagoas, Maceió, 04 fev. 1986. p. A-3.

${ }^{7}$ COLEGIADO irá elaborar agora o programa da Frente Popular. Jornal de Alagoas, Maceió, 04 fev. 1986. p. A-3.

${ }^{8}$ COLEGIADO irá elaborar agora o programa da Frente Popular. Jornal de Alagoas, Maceió, 04 fev. 1986. p. A-3.
} 
comunista". Numa sociedade, como a alagoana, em que o anticomunismo constituiu um forte obstáculo à atuação dos grupos de esquerda durante grande parte do século XX, tendo se aprofundado com a instauração da ditadura em 1964, a fala de Miranda talvez nos forneça um importante indício: a percepção da fragilidade vivida pela Nova República nos seus momentos iniciais. Fragilidade que só desapareceria com a feitura de uma nova Constituição, na qual estariam resguardados os princípios das liberdades democráticas.

Dias depois, em entrevista ao Jornal de Alagoas, o sociólogo Dário Bernardes, membro da Direção Estadual do PCB, defendeu a ampliação da Frente Popular como "única forma de viabilizar um projeto eleitoral para 15 de novembro." (COMUNISTA..., 1986) ${ }^{9}$. Em sua declaração, Bernardes deixou claro que o PCB não estava satisfeito com a atual composição da Frente, para ele ainda muito estreita para se tornar a "Frente Popular" que o seu partido desejava.

Para o dirigente comunista a "Frente Popular", precisava ter muita força orgânica, além de posições corretas, para enfrentar o poderio das duas fortes alternativas que se desenhavam em Alagoas, a saber, o PMDB e o Partido da Frente Liberal (PFL). Segundo Bernardes, como desejavam ganhar as eleições, urgia a necessidade de ampliar a "Frente Popular". A atual composição - PDT, PSB, PT e PCB - ainda era insuficiente. Frisava a importância que setores do PMDB se aglutinassem a Frente, que o MR-8 (CAMURÇA; REIS, 2007) se definisse publicamente sobre a sua adesão, que setores do PFL ingressassem nesse projeto, enfim, que houvesse uma ampliação dos espaços da Frente, principalmente no interior do estado, onde, segundo o comunista, "não somos fortes".

De acordo com Bernardes "a estrutura da Frente Popular na capital era muito boa". A soma dos números de militantes dos quatro partidos integrantes, além dos reforços "naturalmente atraídos" por ela, fazia com que fossem considerados a maior força em termos de capacidade de mobilização. Afirmou ainda que a Frente tinha condições de colocar mais de mil pessoas, em Maceió, trabalhando em seu projeto, ou seja, os militantes e filiados ao PSB, PDT, PT e PCB, além dos integrantes do PMDB, os quais se aproximavam da sua proposta poderiam muito bem levar uma campanha de nível e com uma participação bastante ativa. Concluindo, Bernardes afirmou: "A Frente Popular é fato novo na política alagoana, ela é estimulante. É a novidade que empolga”.

\footnotetext{
${ }^{9}$ COMUNISTA prega a ampliação da Frente Popular em Alagoas. Jornal de Alagoas, Maceió, 15 fev. 1986.
} 
No dia 27 de fevereiro de 1986 o Jornal de Alagoas noticiou sobre o lançamento oficial, para a população, da Frente Popular, que aconteceria em sete de março. Além dos quatro partidos, havia se associado à Frente um grupo de dissidentes do PMDB, formando um novo bloco político. Segundo o jornal, o evento seria caracterizado como um ato público, contando com lideranças expressivas dos partidos que a representavam (FRENTE POPULAR TEM..., 1986) ${ }^{10}$.

Por ocasião do lançamento oficial da Frente Popular, seria distribuído com a população a carta programa, elaborada com base na sugestão dos partidos nela contidos, e que representava os princípios básicos para que a Frente viesse apoiar um candidato ao Governo do estado.

Ainda de acordo com o jornal, na decisão da última reunião do grupo, quando surgiu a proposta de apresentação pública da Frente, foi sugerido que cada um dos partidos se mobilizasse de forma a fazer presente alguns de seus representantes nacionais. Entre os quais já estaria confirmada a presença do senador Jamil Haddad do PSB, e existiam convites, ainda a serem confirmados, do governador Leonel Brizola, pelo PDT, do presidente do PT, Luiz Inácio da Silva, Marcelo Cerqueira, presidente do PSB e Jarbas Vasconcelos, prefeito de Recife, também pelo partido; e Roberto Freire, do PCB, entre outras lideranças.

Entretanto, o local para realização do ato ainda não havia sido confirmado, e deveria ser definido na reunião semanal da Frente Popular, bem como o acerto dos detalhes finais acerca do lançamento, e as definições das lideranças que estariam presentes. A matéria aponta que, no dia anterior, a Frente Popular esteve reunida com o presidente regional do PMDB, Alcides Falcão, para tratar das possibilidades de coligação das oposições, com vistas ao pleito de novembro próximo. Segundo o jornal Gazeta de Alagoas, Falcão, reafirmou seu empenho em buscar a unidade das oposições no estado e disse que o PMDB tinha boa vontade ao entendimento (COLIGAÇÃO..., 1986, p. 2) ${ }^{11}$. Nessa mesma matéria continha a posição do ex-vereador Nilson Miranda (PCB), sustentando que o Partido Comunista Brasileiro não seria obstáculo ao entendimento. Segundo Miranda, "a visão dos comunistas é pelas reformas almejadas

\footnotetext{
${ }^{10}$ FRENTE POPULAR TEM lançamento oficial no dia 7 de março. Jornal de Alagoas, Maceió, 27 fev. 1986.

${ }^{11}$ COLIGAÇÃO das oposições será definida hoje. Gazeta de Alagoas, Maceió, 26 fev. 1986. p. 2-3.
} 
por todos alagoanos e no caso da união das oposições não devem ser consideradas siglas, nem denominações." (COLIGAÇÃO..., 1986, p. 2) $)^{12}$.

O entendimento, porém, parece não ter sido possível. Antes da data prevista para o lançamento da Frente, quatro vereadores do PMDB - Fernando Costa, Guilherme Falcão, Kátia Born e Freitas Neto - deixaram a legenda para o ingresso no PSB, no qual já se encontrava uma ala dissidente do PMDB (EM..., 1986) ${ }^{13}$. Freitas, porém, acabou por se filiar ao PCB, possibilitando ao partido uma representação inédita na Câmara Municipal (ASSUMIDO, 1986) ${ }^{14}$.

O motivo do racha residia na aceitação por parte do PMDB da filiação de Fernando Collor de Melo às fileiras da agremiação. Eleito deputado federal pelo Partido Democrático Social (PDS) em 1982, Collor, que àquela altura já havia sido prefeito de Maceió (1979-1982), surgira na cena política vinculado à Aliança Renovadora Nacional (ARENA), partido criado em 1965 com a finalidade de dar sustentação política ao governo militar. A crise no PMDB se agravou à medida que o nome de Collor foi o escolhido para concorrer ao governo do estado nas eleições de novembro de 1986, o que causou a debandada de um número considerável de seus militantes para outras legendas.

Assim, antes mesmo do seu lançamento, a Frente Popular já se encontrava diante de um dilema. Com a rejeição da proposta de coligação com o PFL, restava à Frente lançar um candidato próprio ao governo. O problema que se apresentava era a escolha de um nome forte capaz de enfrentar tanto o PMDB quanto o próprio PFL (NOME..., 1986) ${ }^{15}$. A rejeição a qualquer entendimento foi frisada por uma declaração do militante do PSB, Eduardo Davino, na qual, ao se posicionar contra o apoio da Frente Popular ao PFL, disparou: "Se o PFL quiser apoiar um candidato da Frente Popular ao governo, é outra coisa." (CONTRA..., s/d) ${ }^{16}$.

A recusa foi oficialmente ratificada no dia 20/03/1986, quando os quatros partidos reunidos decidiram pela não coligação com a chapa PFL/PDS. O presidente do PSB, Dênis Agra, explicou que a Frente Popular não entrou no mérito dos nomes

\footnotetext{
${ }^{12}$ COLIGAÇÃO das oposições será definida hoje. Gazeta de Alagoas, Maceió, 26 fev. 1986. p. 2-3.

${ }^{13}$ EM grupo. Jornal de Alagoas, Maceió, 04 mar. 1986.

${ }^{14}$ ASSUMIDO. Tribuna de Alagoas, Maceió, 25 abr. 1986. O PCB elegeu três deputados estaduais André Papini Gois, José Maria Cavalcante e Moacir Andrade - nas eleições legislativas de 1946, cujos mandatos foram cassados em 1948 depois que a legenda comunista foi proibida pelo Tribunal Superior Eleitoral em 1947. Nilson Miranda, militante do PCB, foi eleito vereador pelo Partido Social Progressista (PSP) em 1963, acabou cassado quando da instauração da Ditadura em 1964.

${ }^{15}$ NOME forte. Jornal de Alagoas, Maceió, 06 mar. 1986.

${ }^{16}$ CONTRA apoio. Gazeta de Alagoas, Maceió, s/d.
} 
apresentados pelo governador José Tavares, interlocutor da proposta para a composição da chapa majoritária, mas optou pela sua rejeição. No encontro com o governador foi apresentada a conclusão da reunião realizada à tarde, na sede do PSB. Participaram da reunião o presidente regional do PDT, Moura Rocha, os militantes do PCB, Cícero Péricles e Nilson Miranda, e do PT e PSB, representados por Régis Cavalcante e Dênis Agra, respectivamente (FRENTE POPULAR..., 1986) ${ }^{17}$.

Agra afirmou ainda que a Frente Popular havia marcado para o dia 6 de abril o anúncio de sua posição sobre o quadro sucessório estadual, não estando descartada a possibilidade de apresentar um nome próprio para concorrer à disputa majoritária. "Não entramos no mérito dos nomes que nos foram apresentados pelo governador José Tavares. O que decidimos foi que não iremos nos coligar com o PFL/PDS”, disse Dênis. Os dois nomes apresentados para discussão com a Frente Popular foram os do deputado federal José Thomaz Nonô Neto e do empresário Geraldo Sampaio. O presidente do PSB adiantou a possibilidade de a Frente Popular vir apoiar a sugestão do PDT para lançamento da candidatura de Geraldo Sampaio ao governo do estado.

Mais de um mês depois, o nome do conselheiro do Tribunal de Contas, Geraldo Sampaio, seria confirmado. O anúncio feito pelo presidente estadual do PDT, José de Moura Rocha, apontava Sampaio como candidato ao governo do estado pela Frente Popular (FRENTE..., 1986) ${ }^{18}$. Segundo Moura, a Frente havia feito um apelo a Geraldo que acabou aceitando o desafio. Ainda de acordo com Moura, esse garantiu que o surgimento do nome de Sampaio não seria repentino, pois desde 1982 seu nome havia sido ventilado, quando se procurava uma forma de trabalho unitário com vistas a presente eleição.

$\mathrm{O}$ presidente do PDT fez questão de frisar que não foram as desavenças ocorridas no PMDB que motivaram o lançamento do candidato da Frente Popular. "O que determinou o lançamento foi a indefinição, a falta de identidade que está existindo dentro do PMDB", afirmou Moura. No seu entender, o PMDB havia se descaracterizado por completo e nada mais seria novidade no partido.

Nilson Miranda (PCB) também apontaria os equívocos tomados pelo PMDB, que, segundo ele, estaria incorrendo "nos mesmos erros do PMDB paulista, ou seja, estaria se comportando com muito triunfalismo e pouca sensibilidade tática" (A

\footnotetext{
${ }^{17}$ FRENTE POPULAR rejeita coligação com PFL/PDS. Gazeta de Alagoas, Maceió, 21 mar. 1986.

${ }^{18}$ FRENTE Popular aponta Geraldo seu candidato. Jornal de Alagoas, Maceió, 09 abr. 1986.
} 
FRENTE..., 1986) ${ }^{19}$. No que tange a outra coligação formada por PFL/PTB/PDS, Miranda afirmaria se tratar de "uma coligação à deriva, sem leme e sem rumo certo". Sobre a posição do PCB com relação às eleições majoritárias, Miranda afirmou:

\begin{abstract}
Estamos lutando pelo fortalecimento e ampliação da Frente Popular, como uma alternativa democrática para a Alagoas. O PCB não entra na discussão de nomes e siglas, nossa preocupação é a definição do projeto político de cada partido ou coligação. A Frente Popular tem se constituído como uma alternativa política para todos que lutam pelo fim do continuísmo em nosso Estado. (A FRENTE..., 1986). ${ }^{20}$
\end{abstract}

A solução apontada, porém, não se concretizou. Geraldo Sampaio acabou por renunciar a sua candidatura à disputa ao governo, alegando, em carta endereçada à Frente Popular, estar impedido por Lei de se filiar a partidos políticos, descartando assim a hipótese de vir a se afastar do Tribunal de Contas, como era exigido pela legislação (SAMPAIO..., 1986) ${ }^{21}$.

Para estar apto à candidatura, Sampaio teria de pedir afastamento até 15 de maio, quando terminaria o prazo para a desincompatibilização de quem desejaria concorrer a cargos eletivos naquele ano. Restava a Frente Popular à procura de um substituto e o nome que parecia mais certo era o do deputado estadual Ronaldo Lessa, que havia recebido o apoio de Sampaio quando esse último formalizou oficialmente sua renúncia. O nome de Lessa foi bem recebido, por exemplo, pelo comunista Nilson Miranda que, em meio a uma reunião do PMDB com a Frente Popular, comentou a possibilidade do deputado do PSB ser candidato a governador e antecipou: "Se ele for eleito, aceito ser o Secretário de Segurança Pública do seu governo.” (SECRETÁRIO..., 1986) ${ }^{22}$.

A incorporação de Lessa junto à Frente Popular, no entanto, esteve longe de acontecer de maneira natural. Nas semanas imediatamente posteriores à sua indicação, ele não foi procurado por nenhum partido para discutir sua possível candidatura ao governo do estado. O deputado revelou que seu nome foi apenas lançado pelo empresário Geraldo Sampaio, que não quis concorrer ao governo, os partidos, segundo ele, ainda não haviam se posicionado. Afirmou ainda que amigos seus o estavam aconselhando a não aceitar o "sacrifício", por entender ser uma "fria", pois sabiam que

\footnotetext{
${ }^{19}$ A FRENTE como alternativa. Jornal de Alagoas, Maceió, 09 abr. 1986.

${ }^{20}$ A FRENTE como alternativa. Jornal de Alagoas, Maceió, 09 abr. 1986.

${ }^{21}$ SAMPAIO também renuncia candidatura ao Governo. Gazeta de Alagoas, Maceió, 29 abr. 1986.

${ }^{22}$ SECRETÁRIO comunista. Gazeta de Alagoas. Maceió, 11 mar. 1986.
} 
sua reeleição à Assembleia Legislativa estava assegurada (FRIA, s/d) ${ }^{23}$. Ainda assim, Lessa disputou as eleições ao Executivo estadual pela Frente Popular.

As indefinições não pararam por aí. Numa matéria chamada "Progressistas querem cargos", o jornal Gazeta de Alagoas demonstrou como as tensões existentes na Frente Popular ultrapassavam as questões programáticas ("PROGRESSISTAS"..., 1986) ${ }^{24}$. Segundo o periódico:

\begin{abstract}
Para quem reivindica a condição de "partidos progressistas", o PSB e o PDT até que tem demonstrado incomum desenvoltura na arte do conchavo fisiológico, reivindicando cargos no governo José Tavares para fechar o acordo que vêm negociando com o PFL e seu aliado, o PDS. ("PROGRESSISTAS"..., 1986). ${ }^{25}$
\end{abstract}

Ainda de acordo com a matéria, perplexos com essa desenvoltura, os outros dois integrantes da "Frente Popular", PCB e PT, estavam cada dia mais próximos da constatação de que "poderiam sobrar, a qualquer momento", afinal se recusavam a participar desse tipo de negociação com políticos governistas. Retratados pelo jornal como "politicamente coerentes e eticamente responsáveis", PCB e PT não queriam jogar para o alto toda uma história de lutas:

O PCB completará seus 63 anos no próximo dia 25, a maioria dos quais vivenciados na clandestinidade, com sangue, suor e lágrimas. O PT, que nasceu da luta dos trabalhadores do ABC paulista, sob os cassetetes dos militares, também tem o dever de preservar suas bandeiras. (“PROGRESSISTAS"..., 1986). ${ }^{26}$

A matéria concluía que "a briga fisiológica por cargos é prática política que, tudo indica, será sepultada em Alagoas no próximo dia 15 de novembro", e os partidos de esquerda, efetivamente progressistas, "tinham compromisso com o futuro".

Em meio aos impasses, a necessidade das definições tornavam-se cada dia mais imperantes. Em julho, o PCB definiu os seus candidatos às eleições: Nilson Miranda concorreria a uma vaga na Assembleia Estadual, enquanto o vereador Freitas Neto disputaria uma das duas vagas ao Senado (CHAPA..., 1986) ${ }^{27}$. Posteriormente, o Partido Liberal (PL) se juntou à Frente Popular e os nomes inicialmente apontados para a

\footnotetext{
${ }^{23}$ FRIA. Gazeta de Alagoas, Maceió, s/d.

24 "PROGRESSISTAS” querem cargos. Gazeta de Alagoas, Maceió, 14 mar. 1986.

25 “PROGRESSISTAS” querem cargos. Gazeta de Alagoas, Maceió, 14 mar. 1986.

26 "PROGRESSISTAS” querem cargos. Gazeta de Alagoas, Maceió, 14 mar. 1986.

${ }^{27}$ CHAPA comunista. Jornal de Alagoas, Maceió, 02 jul. 1986.
} 
disputa do Senado foram os de Lauro Farias (PL), além do já mencionado Freitas Neto $(\mathrm{NO} . . ., 1986)^{28}$. Dois candidatos seriam escolhidos entre os nomes de Mauricio Gondim (PDT), Kátia Moreira (PSB) e Adelmo dos Santos (PT). Desses, Gondim e Moreira foram os indicados (Sem título, 1986) ${ }^{29}$.

Quando do início da campanha, Nilson Miranda foi elogiado pelo Jornal de Alagoas, já que, segundo o periódico, mesmo começando sua campanha atrasado Nilson “já começa a empolgar não só seus camaradas de 'Partidão', bem como os eleitores." (DISCURSO..., 1986) ${ }^{30}$. O jornal afirmou que nos comícios da Frente ele era o mais aplaudido e o que tinha o discurso mais firme. Foi comentado na matéria que sua campanha iria crescer mais ainda depois do início do horário gratuito na TV, pois Nilson havia aprendido a utilizá-la muito bem na campanha para prefeito de Maceió no ano anterior. O jornal concluía que ele sairia na frente de todos, pois era reconhecido como um candidato sério, que não se perde em ataques pessoais e ganha apresentando propostas concretas. Prática essa que vinha mantendo em sua campanha nos comícios da Frente Popular.

O resultado das eleições acabou por sacramentar a derrota da Frente Popular tanto no âmbito executivo quanto legislativo. De um total de 905.630 eleitores, o resultado apontou 112.056 votos em branco $(12,37 \%)$ e 36.023 votos nulos $(3,98 \%)$. Fernando Collor (PMDB) foi eleito governador com um percentual de 52,83\% dos votos enquanto que o candidato da Frente Popular, Ronaldo Lessa obteve 3,97\%.

Quadro 1 - Resultado das eleições para governador ${ }^{31}$

\begin{tabular}{|c|c|c|c|}
\hline $\begin{array}{c}\text { CANDIDATOS A } \\
\text { GOVERNADOR DO } \\
\text { ESTADO }\end{array}$ & COLIGAÇÃO & VOTAÇÃO & PERCENTUAL \\
\hline $\begin{array}{c}\text { Fernando Collor } \\
\text { PMDB }\end{array}$ & $\begin{array}{c}\text { Mudança e Renovação } \\
\text { (PMDB, PCdoB, PTB, PSC) }\end{array}$ & 400.246 & $52,83 \%$ \\
\hline $\begin{array}{c}\text { Guilherme Palmeira } \\
\text { PFL }\end{array}$ & $\begin{array}{c}\text { Aliança Liberal Cristã } \\
\text { (PFL, PDS, PDC) }\end{array}$ & 327.232 & $43,20 \%$ \\
\hline $\begin{array}{c}\text { Ronaldo Lessa } \\
\text { PSB }\end{array}$ & $\begin{array}{c}\text { Frente Popular } \\
\text { (PSB, PDT, PT, PCB, PL) }\end{array}$ & 30.073 & $3,97 \%$ \\
\hline
\end{tabular}

Fonte: TRIBUNAL REGIONAL DE ALAGOAS, 1986.

\footnotetext{
${ }^{28}$ NO mesmo dia. Jornal de Alagoas, Maceió, 02 jul. 1986.

${ }^{29}$ Sem título. Gazeta de Alagoas, Maceió, 02 jul. 1986.

${ }^{30}$ DISCURSO firme. Jornal de Alagoas, Maceió, 01 set. 1986.

${ }^{31}$ TRIBUNAL REGIONAL ELEITORAL DE ALAGOAS. Resultado das eleições para governador. Maceió: Tribunal Regional Eleitoral de Alagoas, 1986. Disponível em: <http://www.tse.jus.br/internet/eleicoes/resultado_1986.htm>. Acesso em: 10 fev. 2015.
} 
Para o Senado, foram eleitos o ex-governador Divaldo Suruagy (PFL) e o deputado Teotônio Vilela Filho (PMDB). Os dois candidatos da Frente Popular, Luis Farias e Freitas Neto amargaram, respectivamente, penúltimo e último lugares na votação.

Quadro 2 - Resultado das eleições para senador ${ }^{32}$

\begin{tabular}{|c|c|c|}
\hline $\begin{array}{c}\text { CANDIDATOS A SENADOR DA } \\
\text { REPÚBLICA }\end{array}$ & COLIGAÇÃo & VOTAÇÃo \\
\hline $\begin{array}{c}\text { Divaldo Suruagy } \\
\text { PFL }\end{array}$ & $\begin{array}{c}\text { Aliança Liberal Cristã } \\
\text { (PFL, PDS, PDC) }\end{array}$ & 334.137 \\
\hline $\begin{array}{c}\text { Teotônio Vilela Filho } \\
\text { PMDB }\end{array}$ & $\begin{array}{c}\text { Mudança e Renovação } \\
\text { (PMDB, PCdoB, PTB, PSC) }\end{array}$ & 332.904 \\
\hline $\begin{array}{c}\text { Mendonça Neto } \\
\text { PMDB }\end{array}$ & $\begin{array}{c}\text { Mudança e Renovação } \\
\text { (PMDB, PCdoB, PTB, PSC) }\end{array}$ & 202.408 \\
\hline $\begin{array}{c}\text { João Lyra } \\
\text { PMDB }\end{array}$ & $\begin{array}{c}\text { Mudança e Renovação } \\
\text { (PMDB, PCdoB, PTB, PSC) }\end{array}$ & 121.709 \\
\hline $\begin{array}{c}\text { Luiz Mendes de Barros } \\
\text { PFL }\end{array}$ & $\begin{array}{c}\text { Aliança Liberal Cristã } \\
\text { (PFL, PDS, PDC) }\end{array}$ & 70.555 \\
\hline $\begin{array}{c}\text { João Azevedo } \\
\text { PFL }\end{array}$ & $\begin{array}{c}\text { Aliança Liberal Cristã } \\
\text { (PFL, PDS, PDC) }\end{array}$ & 61.324 \\
\hline $\begin{array}{c}\text { Rubens Vilar } \\
\text { PMDB }\end{array}$ & $\begin{array}{c}\text { Mudança e Renovação } \\
\text { (PMDB, PCdoB, PTB, PSC) }\end{array}$ & 34.719 \\
\hline $\begin{array}{c}\text { Luiz Farias } \\
\text { PSB }\end{array}$ & $\begin{array}{c}\text { Frente Popular } \\
\text { (PSB, PDT, PT, PCB, PL) }\end{array}$ & 26.531 \\
\hline $\begin{array}{c}\text { Frente Popular } \\
\text { (PSB, PDT, PT, PCB, PL) }\end{array}$ & 25.171 \\
\hline $\begin{array}{c}\text { João Vicente Freitas Neto } \\
\text { PSB }\end{array}$ & \begin{tabular}{c} 
PML \\
\hline
\end{tabular} & \\
\hline
\end{tabular}

Fonte: TRIBUNAL REGIONAL DE ALAGOAS, 1986.

As nove vagas disponíveis para a Câmara Federal foram ocupadas pelo PMDB e pelo PFL, cada um ocupando quatro cadeiras, ficando a vaga restante com o PTB. Na Assembleia Estadual, foram eleitos 27 parlamentares, com as bancadas assim distribuídas segundo o número de vagas: PFL, dez; PMDB, sete; PTB, seis; PDT, três; PSB uma. Nos dados online do TRE-AL, não encontrei as relações nominais dos parlamentares votados, apenas a distribuição dos eleitos por seus respectivos partidos ${ }^{33}$.

32 TRIBUNAL REGIONAL ELEITORAL DE ALAGOAS. Resultado das eleições para senador. Maceió: Tribunal Regional Eleitoral de Alagoas, 1986. Disponível em: <http://www.tse.jus.br/internet/eleicoes/resultado_1986.htm>. Acesso em: 10 fev. 2015.

33 Apesar de não constar no website do Tribunal Regional de Alagoas a lista dos Deputados Federais eleitos, por intermédio da página da Câmara Federal (www2.camara.leg.br) pode-se consultar nominalmente quais os parlamentares mais votados no pleito. 
Em um ensaio publicado em 1993, o economista Cícero Péricles de Carvalho dirigente do PCB em 1986 - afirmou que, nas eleições de novembro de 1986, as duas grandes coligações em disputa contavam com todos os elementos para vencer uma eleição: apoio financeiro dos grandes grupos econômicos, espaço nas rádios e televisões, estrutura material de fortes chapas proporcionais (CARVALHO, 1993, p. 48). O governador em exercício, José Tavares, que havia tido o seu nome preterido para disputar o governo pelas forças situacionistas de então, deu apoio ostensivo à candidatura do PMDB numa atitude de retaliação contra as lideranças do PFL/PDS, desequilibrando a eleição a favor de Fernando Collor. Nesse quadro, venceu uma parcela da velha classe política, reconduzida ao poder com uma nova roupagem, que aparentava um suposto interesse em viabilizar as mudanças que o dramático quadro social exigia e que se ampliara sob os vários governos estaduais da ARENA/PDS (CARVALHO, 1993, p. 49).

\section{O PCB e a Frente Popular: esperança e decepção}

No plano político geral, o PCB viveu um impasse em relação à participação no processo eleitoral constituinte. Marco Aurélio Santana aponta como a orientação política do partido - que se refletia na sua postura no campo sindical -, de lutar para negociar, negociar para mudar (SANTANA, 2001), trouxera uma série de problemas tanto na esfera política institucional quanto no movimento operário. De acordo com o autor, a postura assumida pelos comunistas acabava por fazer com que esses se colocassem numa encruzilhada, se, de um lado, a sua estratégia de fornecer apoio ao processo de transição para a Nova República e, posteriormente à Aliança Democrática acabou por transformá-lo num avalista do governo Sarney; de outro lado, a postura de enfrentamento e de crítica à política governamental possibilitava o crescimento do PT e da CUT no seio movimento sindical.

Ainda de acordo com Santana, o PCB, de forma geral, participará de todo o processo constituinte indicando, além de sua importância, os perigos nele embutidos. Preocupava-se com as ações dos grupos mais radicais baseando-se na lógica da fragilidade da transição e na possibilidade, sempre temida pelo partido, de recuo (SANTANA, 2001, p. 261).

Dulce Pandolfi afirma que a direção do PCB admitia a pequena inserção do partido (PANDOLFI, 1995). Entretanto, segundo a autora, a crença era a de que o 
crescimento e o fortalecimento do partido seriam uma decorrência natural do avanço da democracia, um desdobramento da transição democrática que só completaria o seu ciclo com a promulgação de uma nova Constituição.

O ponto crucial nessa encruzilhada resumia-se no seguinte: o antigo partido da insurreição e da revolução estava se afirmando, na década de 1980, como o partido da legalidade e da ordem. Pandolfi chama a atenção para a preocupação de diversos militantes com a identidade do PCB, a qual não era apenas retórica ou simples decorrência da diversidade interna ou da convivência (pacífica ou conflituosa) das várias correntes que se depararam com dilemas constitutivos que fizeram a história do PCB (PANDOLFI, 1995, p. 232).

Em terras alagoanas, a formação da Frente Popular foi encarada como um manancial de possibilidades pelo PCB. Sua participação na Frente foi pautada pelo documento "Programação da Campanha", cujo primeiro parágrafo dá mostras das expectativas que o partido tinha sobre o pleito: "Nossa meta é a eleição de um deputado estadual. O nome escolhido foi o do camarada Nilson Miranda." (MAJELLA, 2011, p. $183-184)^{34}$. Estipulando a existência de um eleitorado de 950.000 votantes, 250 mil na capital e 700 mil no interior, o documento previa, segundo "cálculos dos conhecedores da política eleitoral alagoana", que a Frente Popular deveria eleger entre quatro e cinco deputados estaduais e um deputado federal, podendo ampliar esse número. Para eleição de um deputado estadual, seria necessário entre 7 e 8 mil votos para eleger alguém da Frente Popular.

O documento previa que o trabalho deveria ser centrado na capital. Maceió, com 28 bairros, 47 favelas e 16 conjuntos habitacionais, merecia toda a atenção num eleitorado de mais de 250 mil votos. Sabendo das limitações que possuíam, os comunistas reconheciam "o eleitorado da capital como mais acessível às nossas propostas". A militância estava concentrada em Maceió e isso faria os seus recursos serem otimizados. O desafio residia na expansão para o interior do estado. Era preciso fazer um levantamento minucioso de todos os contatos nos municípios alagoanos partidários ou não -, para que se pudesse realizar a campanha eleitoral. O trabalho deveria ser concentrado nos municípios onde o PCB estava organizado. Nas viagens da Frente Popular, qualquer iniciativa da Frente Popular deveria ser aproveitada em relação aos seus candidatos.

\footnotetext{
${ }^{34}$ MAJELLA, Geraldo (Org.). PCB em Alagoas: documentos (1982-1990). Maceió: [s. n.], 2011. (Coleção Documentos Alagoanos). p. 183-184.
} 
A logística da campanha definiu que os comunistas deveriam aproveitar o máximo que a estrutura da Frente Popular pudesse lhes oferecer. A preocupação com material gráfico, carros-de-som e, principalmente, com a imprensa foram levantados. Uma reunião deveria acontecer no mais breve espaço de tempo para discutir o espaço da campanha pecebista nos jornais, rádios e TV.

No fim do documento, um ultimato: "Nós não podemos repetir os erros de lançamento das campanhas dos outros candidatos. Temos de fazer um lançamento aberto". A ideia era fazer uma marcha, no centro de Maceió, com fogos, pessoal com camisetas e material de campanha para distribuir. Na Rua do Comércio seria feito um comício rápido.

As pistas fornecidas pelo documento nos sugerem uma autoimagem do partido no sentido de ainda se entender como uma força política relevante, o que, em se tratando da esquerda brasileira ao longo do século XX, essa afirmação não configura nenhum exagero. Mesmo antevendo as dificuldades, eles acreditavam que poderiam obter êxito e, talvez, mais que acreditar, confiavam cegamente nisso. Os indícios? O candidato ao Senado já ocupava uma vaga de vereador na Câmara municipal da capital, o candidato ao legislativo estadual era um militante respeitado pela sua história, obstinadamente perseguido pelos adversários políticos. O que talvez não entendessem é que os tempos haviam mudado, a influência do partido junto aos trabalhadores agora tinha concorrentes. O Partido da Classe Operária agora era um dos partidos entre os outros existentes.

Diante da derrota sofrida, conforme os dados antecipados acima, era hora de se fazer uma avaliação do que causou o infortúnio para a Frente. No documento "Subsídios para a análise das eleições" (MAJELLA, 2011, p. 193-196) ${ }^{35}$ foi feita a avaliação de que, em termos gerais:

\footnotetext{
As grandes massas dos mais diversos estamentos da sociedade brasileira votaram no projeto de mudança do PMDB; ofereceram um voto de confiança à Nova República; votaram pela consolidação do processo democrático e na renovação das lideranças políticas de norte a sul do país. (MAJELLA, 2011, p. 193-196). ${ }^{36}$
}

\footnotetext{
${ }^{35}$ MAJELLA, Geraldo (Org.). PCB em Alagoas: documentos (1982-1990). Maceió: [s. n.], 2011. (Coleção Documentos Alagoanos). p. 193-196.

${ }^{36}$ MAJELLA, Geraldo (Org.). PCB em Alagoas: documentos (1982-1990). Maceió: [s. n.], 2011. (Coleção Documentos Alagoanos). p. 193-196.
} 
Para os comunistas, o resultado das eleições refletia o avanço das forças democráticas, a consolidação da democracia e, mesmo não sendo a composição da Assembleia Nacional Constituinte na sua totalidade progressista, a grande votação obtida pelo PMDB e demais forças progressistas, sob palavras de ordem de mudanças, Reforma Agrária, Constituinte, iria influir certamente na tendência do Parlamento quanto a Constituição democrática.

Em termos nacionais, os resultados eleitorais obtidos pelo Partido foram avaliados como modestos; não traduziam em absoluto a influência que a linha política do Partido exercia no processo político de consolidação democrática. Foram eleitos três deputados constituintes (Roberto Freire, Fernando Sant'ana e Augusto Carvalho), enquanto seu aliado preferencial, o PMDB, elegeu a maior bancada, bem como praticamente todos os governadores. Fabricio Pereira da Silva demonstra que o PCB participou dos trabalhos da Constituinte - tão valorizada pelo partido nos dizeres do autor - extremamente enfraquecido, sem conseguir intervir tão diretamente em seus resultados - malgrado a atuação destacada de seus parlamentares (SILVA, 2005).

No âmbito estadual a autocrítica foi mais severa. A Frente Popular, na qual o Partido se engajara eleitoralmente, havia se lançado às eleições "com um discurso não entendido pelas massas como progressista e de conteúdo de mudança, haja vista a insignificante votação obtida em Maceió, o centro político do Estado". A Frente Popular, muito heterogênea, não se lançou disciplinada e organizadamente na campanha, sendo o PCB "a força mais consequente, leal e atuante".

Em termos partidários, a insignificante (em relação ao esforço empenhado pelo Partido) votação obtida pelo Partido traduzia a sua absoluta desvinculação das massas. Nenhum dos dirigentes comunistas pertencia a uma direção sindical, a uma organização de massas, ou estava vinculado ao trabalho ativo nas organizações de massa, e, portanto, não seria capaz de influir em sua comunidade no processo eleitoral. Segundo o documento, o Partido "lançou-se com denodo ao trabalho eleitoral, principalmente os camaradas jovens". Um dos principais erros apontados foi a não priorização, ao término da campanha, dos setores ou locais onde o partido poderia obter maior votação, como nos bairros que concentravam massas significativas de trabalhadores como Fernão Velho, Rio Largo, Utinga, etc.

A propaganda foi avaliada como falha e dispersiva, pois não havia levantado as palavras de ordem do Partido. Para se fugir ao "estigma comunista", elas foram omitidas. O candidato, "não sendo um camarada de massas", teve um desempenho 
discutível, "caindo as vezes no terreno burguês da retaliação, no lugar-comum dos demais candidatos dos partidos burgueses". Porém, havia elementos positivos. Em termos políticos gerais, as forças mais retrógradas no estado foram derrotadas: o "malufismo" e a candidatura do usineiro João Lyra. A votação consagrada a Collor de Melo, caracterizado no documento como "travestido de peemedebista foi sobre o seu discurso de mudanças e sobre o seu 'jeito simpático', que influiu grandemente no eleitorado feminino".

O PCB não saiu fortalecido numericamente, organicamente ou financeiramente do processo eleitoral - segundo sua própria avaliação. Durante a campanha eleitoral o candidato a deputado estadual recusava-se a ir às massas participar dos atos na capital e interior. As alianças com os deputados federais não foram proveitosas, e Freitas Netto não vinculou sua campanha à de Nilson Miranda, principalmente nos bairros e no interior, onde os candidatos - sobretudo Nilson - não acompanhavam a Frente Popular.

Sobre os partidos componentes da Frente Popular, esses foram caracterizados a partir de uma atuação diferenciada. O PDT foi apontado como a principal força desagregadora da Frente, criando um clima de desconfiança e divisão. O PL "como era se de esperar" havia atuado "como uma aglomeração de oportunistas." (MAJELLA, 2011, p. 195) ${ }^{37}$. O PT foi avaliado como confuso, pouco contribuindo para a Frente. A exceção foi o PSB, cujo importante papel desempenhado, no discurso e na atuação conjunta com o PCB, foi a força motriz da unidade e seu principal referencial político. Para os comunistas, uma coisa ficava clara: nenhum desses partidos teria ligação com as massas, apesar do discurso progressista.

A participação na Frente Popular foi avaliada como a melhor opção política, tendo em vista os projetos do PMDB ou do PFL serem inviáveis para o PCB, além de não representar nenhum avanço das forças democráticas em Alagoas.

Gerard Vincent (1992, p. 438), ao estudar alguns aspectos da vida privada dos comunistas, chama atenção para um traço particular da sua cultura política, o que o autor chama de "recusa pelo 'real"”. Partindo do suposto que essa recusa não é característica específica do militante comunista, sendo ela constitutiva da vida privada em geral, o autor afirma que a negação de uma realidade contestadora do arcabouço teórico, defendido a priori pelo comunista, serve mais para uma tranquilização pessoal do que para persuadir o outro. Derrotados nas primeiras eleições que disputavam com

\footnotetext{
37 MAJELlA, Geraldo (Org.). PCB em Alagoas: documentos (1982-1990). Maceió: [s. n.], 2011. (Coleção Documentos Alagoanos). p. 195.
} 
legenda própria em mais de quarenta anos, os comunistas continuaram. Nos pleitos de 1988 e de 1990, eles novamente se reagruparam, estabeleceram metas e prioridades e foram à luta. Num mundo que se transformava em um ritmo cada vez mais avassalador, os comunistas encarnados num Sísifo continuavam a empurrar a pedra até o topo da montanha, e de novo e de novo...

\section{Considerações finais}

Ao longo do texto, procurou-se abordar a formação da Frente Popular alagoana nas eleições estaduais de 1986, bem como a participação do PCB nela. Por se tratar de uma pesquisa em fase inicial de desenvolvimento, nenhum dos resultados acima expostos pretende ter qualquer caráter conclusivo. Minha intenção residiu tão somente em demonstrar como a arregimentação da Frente, marcada por uma série de impasses, mas também por avanços, procurou constituir uma alternativa, uma terceira via às duas forças políticas existentes até então, o PMDB e o PFL.

Quanto ao PCB, sua atuação esteve pautada pelos limites tanto nacionais quanto locais que acometiam o partido naquela metade de década. Enredado em contradições que vieram a lhe custar um grande preço político, o partido procurava encontrar o seu lugar na recém-inaugurada Nova República. Mesmo com a derrota, o partido seguiu em frente, a batalha perdida não abateu seus militantes. E como haveria de acontecer ainda mais algumas vezes, a crença de que na próxima disputa tudo seria diferente prevaleceu entre os comunistas. 


\section{REFERÊNCIAS}

\section{Fontes primárias}

“PROGRESSISTAS” querem cargos. Gazeta de Alagoas, Maceió, 14 mar. 1986.

A FRENTE como alternativa. Jornal de Alagoas, Maceió, 09 abr. 1986.

ARQUIVO PÚBLICO DE ALAGOAS. Fundo Geraldo Majella. Governo do Estado de Alagoas: Maceió, 2010. Disponível em: <http://www.an.gov.br/mr/Seguranca/Principal.asp>. Acesso em: 3 fev. 2015.

ASSUMIDO. Tribuna de Alagoas, Maceió, 25 abr. 1986.

CHAPA comunista. Jornal de Alagoas, Maceió, 02 jul. 1986.

COLEGIADO irá elaborar agora o programa da Frente Popular. Jornal de Alagoas, Maceió, 04 fev. 1986. p. A-3.

COLIGAÇÃO das oposições será definida hoje. Gazeta de Alagoas, Maceió, 26 fev. 1986. p. 2 e 3.

COMUNISTA prega a ampliação da Frente Popular em Alagoas. Jornal de Alagoas, Maceió, 15 fev. 1986.

CONTRA apoio. Gazeta de Alagoas, Maceió, s/d.

DISCURSO firme. Jornal de Alagoas, Maceió, 01 set. 1986.

EM grupo. Jornal de Alagoas, Maceió, 04 mar. 1986.

FRENTE Popular aponta Geraldo seu candidato. Jornal de Alagoas, Maceió, 09 abr. 1986.

FRENTE POPULAR rejeita coligação com PFL/PDS. Gazeta de Alagoas, Maceió, 21 mar. 1986.

FRENTE POPULAR TEM lançamento oficial no dia 7 de março. Jornal de Alagoas, Maceió, 27 fev. 1986.

FRIA. Gazeta de Alagoas, Maceió, s/d.

MAJELLA, Geraldo (Org.). PCB em Alagoas: documentos (1982-1990). Maceió: [s. n.], 2011. (Coleção Documentos Alagoanos).

NO mesmo dia. Jornal de Alagoas, Maceió, 02 jul. 1986.

NOME forte. Jornal de Alagoas, Maceió, 06 mar. 1986. 
SAMPAIO também renuncia candidatura ao Governo. Gazeta de Alagoas, Maceió, 29 abr. 1986.

SECRETÁRIO comunista. Gazeta de Alagoas. Maceió, 11 mar. 1986.

Sem título. Gazeta de Alagoas, Maceió, 02 jul. 1986.

TRIBUNAL REGIONAL ELEITORAL DE ALAGOAS. Resultado das eleições para governador. Maceió: Tribunal Regional Eleitoral de Alagoas, 1986. Disponível em: <http://www.tse.jus.br/internet/eleicoes/resultado_1986.htm>. Acesso em: 10 fev. 2015.

TRIBUNAL REGIONAL ELEITORAL DE ALAGOAS. Resultado das eleições para senador. Maceió: Tribunal Regional Eleitoral de Alagoas, 1986. Disponível em: <http://www.tse.jus.br/internet/eleicoes/resultado_1986.htm>. Acesso em: 10 fev. 2015.

\section{Fontes secundárias}

AARÃO REIS, Daniel. Ditadura e democracia no Brasil. Rio de Janeiro: Jorge Zahar, 2014.

AARÃO REIS, Daniel. Luís Carlos Prestes. São Paulo: Companhia das Letras, 2014.

BERSTEIN. Serge. Os Partidos. In: RÉMOND, René (Org.). Por uma história política. Rio de Janeiro: FGV, 2003.

CAMURÇA, Marcelo Ayres; REIS, Daniel Aarão. O Movimento Revolucionário 8 de Outubro (MR-8). Da luta armada contra a ditadura à luta eleitoral no PMDB. In: FERREIRA, Jorge; REIS, Daniel Aarão (Org.). As esquerdas no Brasil: revolução e democracia (1964...). vol. 3. Rio de Janeiro: Civilização Brasileira, 2007.

CARVAlHO, Cícero Péricles. Alagoas 1980-1992: a esquerda em crise. Maceió: EDUFAL/LUMEN/ENGENHO, 1993.

CARVALHO, Maria Alice Rezende. Breve história do "comunismo democrático" no Brasil. In: FERREIRA, Jorge; REIS, Daniel Aarão. As esquerdas no Brasil: revolução e democracia (1964...). vol. 3. Rio de Janeiro: Civilização Brasileira, 2007.

DEL ROIO, Marcos. Prefácio. In: PINHEIRO, Milton (Org.). O que resta da transição. São Paulo: Boitempo, 2014.

GORENDER, Jacob. Combate nas trevas. A esquerda brasileira: das ilusões perdidas à luta armada. $4^{\text {a }}$ ed. São Paulo: Ática, 1990.

PANDOLFI, Dulce. Camaradas e companheiros: história e memória do PCB. Rio de Janeiro: Relumé-Dumará, 1995.

PANDOLFI, Dulce Chaves. A trajetória de Luís Carlos Prestes. In: FERREIRA, Jorge; REIS, Daniel Aarão. As esquerdas no Brasil: revolução e democracia (1964...). vol. 3. Rio de Janeiro: Civilização Brasileira, 2007. 
PRESTES, Anita Leocádia. Luiz Carlos Prestes e a luta pela democratização da vida nacional após a anistia de 1979. In: PINHEIRO, Milton (Org.). O que resta da transição. São Paulo: Boitempo, 2014.

REIS, Daniel Aarão. A revolução faltou ao encontro: os comunistas no Brasil. Rio de Janeiro: Brasiliense, 1990.

REIS, Daniel Aarão. Luís Carlos Prestes. São Paulo: Companhia das Letras, 2014a.

REIS, Daniel Aarão. Ditadura e democracia no Brasil. Rio de Janeiro: Jorge Zahar, 2014b.

SANTANA, Marco Aurélio. Homens partidos: comunistas e sindicatos no Brasil. São Paulo: Boitempo, 2001.

SEGATTO, José Antonio; SANTOS, Raimundo. A valorização da política na trajetória pecebista: dos anos 1950 a 1991. In: REIS, Daniel Aarão; RIDENTI, Marcelo (Org.). História do Marxismo do Brasil. Vol. 6. Campinas: Editora da UNICAMP, 2007.

SILVA, Fabrício Pereira. Utopia dividida: crise e extinção do PCB (1979-1992). 2005. Dissertação (Mestrado em História) - Universidade Federal do Rio de Janeiro, Programa de Pós-graduação em História, Rio de Janeiro, 2005.

TEIXEIRA, Francisco Carlos. Crise da ditadura militar e o processo de abertura política no Brasil. In: FERREIRA, Jorge; DELGADO, Lucilia de Almeida Neves (Org.). O Brasil Republicano. O tempo da ditadura: regime militar e movimentos sociais em fins do século XX. vol. 4. $4^{\text {a }}$ ed. Rio de Janeiro: Civilização Brasileira, 2010.

VICENT, Gerard. Ser comunista? Uma maneira de ser. In: PROST, Antoine; VICENT, Gerard (Org.). História da vida privada. vol. 5. (da Primeira Guerra a nossos dias). São Paulo: Companhia das Letras, 1992. 